\title{
Relaxation of Bulk Metallic Glasses Studied by Mechanical Spectroscopy
}

\author{
Jichao Qiao, ${ }^{\dagger, t}$ Jean-Marc Pelletier, ${ }^{*,+,}$ and Riccardo Casalini ${ }^{\S}$ \\ ${ }^{\dagger}$ Université de Lyon, CNRS, Lyon, France \\ ${ }^{\ddagger}$ INSA-Lyon, MATEIS UMR5510, F-69621 Villeurbanne, France \\ ${ }^{\S}$ Chemistry Division, Naval Research Laboratory, Code 6120, Washington, D.C. 20375-5342, United States
}

ABSTRACT: The relaxational dynamics in metallic glasses (MGs) is investigated by using mechanical spectroscopy. The spectra show that in MGs there are two relaxations: (i) the $\alpha$ relaxation, linked to the glass transition, as observed in other classes of amorphous materials; and (ii) the $\beta$ relaxation, well observed below the glass transition, with an intensity strongly dependent on the MG composition, the nature of which has been linked to the local microstructure of MGs. For the
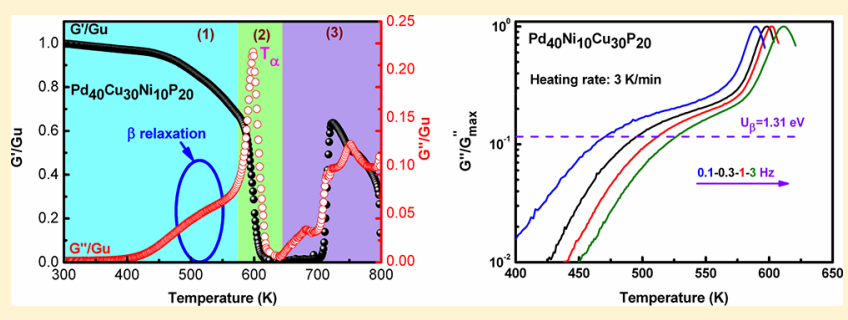
investigated MGs we find that the intensity and relaxation time of the $\beta$ relaxation depends, in a reproducible fashion, on the thermal history of the samples. During aging experiments, the intensity decreases (as well as the $\tau_{\beta}$ ) with a time dependence described well by a stretched exponential, with an exponent $\beta_{\text {aging }}$ independent of the driving frequency. Moreover, we find that the activation energy $U_{\beta}$ and the peak temperature $T_{\beta \mathrm{p}}$ of the $\beta$ relaxation follow the approximate relationship: $U_{\beta} \approx 31.5 R T_{\beta \mathrm{p}}$ (for driving frequency $1 \mathrm{~Hz}$ ), indicating that the high temperature limit of the peak frequency is approximately the same for all the MGs investigated. Finally, the frequency separation of the $\alpha$ and $\beta$ processes in the mechanical loss spectra for La-and Pd-based metallic glasses is tested against the prediction of the Coupling Model.

\section{INTRODUCTION}

A fundamental aspect of the physics of the glass transition for all different types of amorphous materials (i.e., amorphous polymers, glassy oxides, and metallic glasses) is the study of the dependence of the material dynamics properties on the thermodynamic variables. ${ }^{1,2}$ The dynamical properties are generally measured studying the relaxation behavior with techniques like dielectric and mechanical spectroscopy. ${ }^{3-9}$ In the spectra are generally observed at least two relaxations: (i) the $\alpha$ relaxation, observed above the glass transition temperature, is a universal feature of all the amorphous materials and is attributed to the cooperative motion of the molecules; (ii) the $\beta$ relaxation, sometimes called Johari-Goldstein (JG) relaxation, is detected at lower temperature (or higher frequency domain), and is often much smaller than the $\alpha$-process and not always evident in all amorphous materials. ${ }^{10-14}$ The $\beta$ relaxation is considered a universal feature of amorphous polymers, with the temperature dependence of its peak frequency described below $T_{g}$ by an Arrhenius law. ${ }^{2}$ The nature of the $\beta$ relaxation in polymers is attributed to local noncooperative motions of the polymer segments for JG-type relaxations, while secondary relaxation associated with the side group motion is generally considered non-JG relaxation. ${ }^{10}$ Moreover, the $\beta$ relaxation is connected to the plasticity in amorphous polymers. Indeed, many polymers present a large plastic deformation between $T_{\beta \mathrm{p}}$ (temperature corresponding to the $\beta$ relaxation) and $T_{\alpha}$ (temperature corresponding to the $\alpha$ relaxation). ${ }^{15,16}$ An empirical relationship between the activation energy of the $\beta$ relaxation $U_{\beta}$ and glass transition temperature $T_{g}$ in amorphous polymers was established as $U_{\beta}=$ (26 \pm 2$) R T_{g}$ ( $R$ is gas constant). ${ }^{17}$ In amorphous materials, as the JG relaxation occurs before the $\alpha$ process it is often considered as its noncooperative precursor. ${ }^{17,18}$

Unlike the $\beta$ relaxation, the temperature dependence of the $\alpha$ relaxation peak frequency shows a behavior that cannot be described with an Arrhenius equation, characterized by an activation energy increasing with decreasing temperature that can be described by a Vogel-Fulcher-Tamman (VFT)-type behavior. $^{2}$

Metallic glasses, due to their more recent development, have been investigated much less than other types of glasses. Thanks to their metallic nature and the lack of a crystalline lattice, grain boundaries, and dislocations metallic glasses exhibit a series of unique physical and mechanical properties, such as large elastic deformation, high strength, and excellent corrosion resistance. $^{19-23}$ The dynamics of the atomic rearrangements in metallic glasses is generally studied using mechanical relaxation. Unlike the case of amorphous polymers, only for some families of metallic glasses is a well separated $\beta$ relaxation evident. A pronounced $\beta$ relaxation was observed in Pd-based, ${ }^{24}$ Labased, ${ }^{13,25-28}$ and Nd-based ${ }^{29}$ metallic glasses. In the cases in which a well resolved $\beta$ relaxation is not observed, it is present

Received: July 8, 2013

Revised: September 2, 2013

Published: September 26, 2013 
only as a shoulder on the low temperature (or high frequency) side of the $\alpha$ relaxation spectra. This process is often called the "excess wing". Examples of the spectra for few families of MGs are reported by Figure 1.

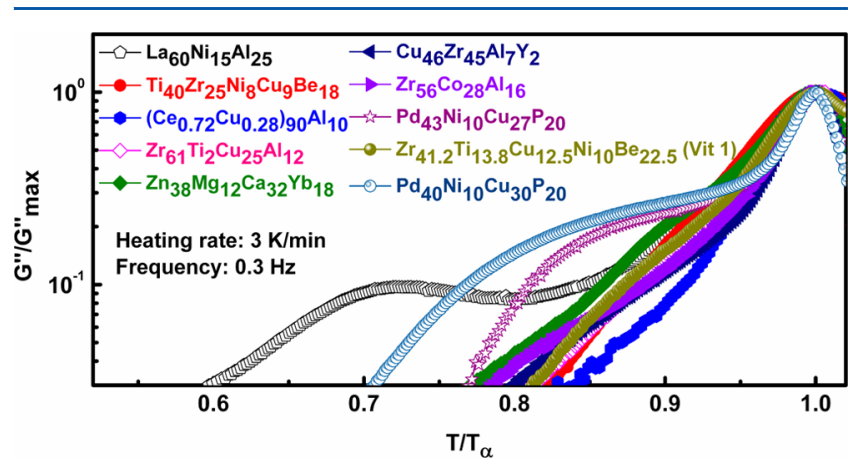

Figure 1. Temperature dependence of the loss modulus $G^{\prime \prime} / G^{\prime \prime}{ }_{\max }$ ( $G^{\prime \prime}{ }_{\max }$ is the peak of $\alpha$ relaxation in the loss modulus) in various bulk metallic glasses (heating rate: $3 \mathrm{~K} / \mathrm{min}$ and driving frequency: $0.3 \mathrm{~Hz}$ ): $\mathrm{La}_{60} \mathrm{Ni}_{15} \mathrm{Al}_{25}{ }^{13} \mathrm{Ti}_{40} \mathrm{Zr}_{25} \mathrm{Ni}_{8} \mathrm{Cu}_{9} \mathrm{Be}_{18}{ }^{30} \quad\left(\mathrm{Ce}_{0.72} \mathrm{Cu}_{0.28}\right)_{90} \mathrm{Al}_{10},{ }^{31}$ $\mathrm{Zr}_{61} \mathrm{Ti}_{2} \mathrm{Cu}_{25} \mathrm{Al}_{12}, \quad \mathrm{Zn}_{38} \mathrm{Mg}_{12} \mathrm{Ca}_{12} \mathrm{Yb}_{18}, \quad \mathrm{Cu}_{46} \mathrm{Zr}_{45} \mathrm{Al}_{7} \mathrm{Y}_{2}, \mathrm{Zr}_{56} \mathrm{Co}_{28} \mathrm{Al}_{16}$, $\mathrm{Pd}_{43} \mathrm{Ni}_{10} \mathrm{Cu}_{27} \mathrm{P}_{20}$, Vit1 and $\mathrm{Pd}_{40} \mathrm{Ni}_{10} \mathrm{Cu}_{30} \mathrm{P}_{20}$, respectively.

Based on the mechanical relaxation results, it was found by several authors that the $\beta$ relaxation is connected to the physical and mechanical properties in metallic glasses: (i) the $\beta$ relaxation, when it exists, is connected with the plastic deformation in La-based metallic glass; ${ }^{27}$ (ii) the activation energy $U_{\beta}$ of the $\beta$ relaxation in metallic glasses is related to the potential energy barriers of the shear transformation zones (STZs) $W_{\mathrm{STZ}}: U_{\beta} \approx 26( \pm 2) R T_{g} \approx \mathrm{W}_{\mathrm{STZ}}{ }^{32}$ (iii) the $\beta$ relaxation is linked to the diffusion motion of the smallest constituent atom in metallic glasses (i.e., $\mathrm{Zr}$ - and Pd-based metallic glasses); ${ }^{26}$ (iv) the $\beta$ relaxation depends on the chemical interactions among all the constituting atoms. ${ }^{33}$ However, no obvious correlation between the existence of the $\beta$ relaxation and the compressive plasticity has been observed in $\mathrm{La}_{62} \mathrm{Al}_{14}\left(\mathrm{Cu}_{5 / 6} \mathrm{Ag}_{1 / 6}\right)_{14} \mathrm{Ni}_{5} \mathrm{Co}_{5}$ bulk metallic glass at room temperature. ${ }^{34}$

The $\beta$ relaxation has been attributed to structural heterogeneity in metallic glasses and is linked to local movements of "weak spots" or "soft zones" (i.e., free volume, flow defects, or quasi-point defects, ${ }^{35-37}$ liquid-like sites, ${ }^{38,39}$ weakly bonded zones, ${ }^{40,41}$ loose packing regions ${ }^{42}$ ). The presence of structural heterogeneity in nano- or microscale domain has been verified in metallic glasses by transmission electron microscopy (TEM) and simulation method. ${ }^{43-45}$ Unfortunately, the precise physical nature of the $\beta$ relaxation is still far from being understood.

As we discussed above, by contrast with the conventional alloys, metallic glasses present liquid-like disorder features due to the absence of long-range order. The deformation mechanisms of the traditional metals, i.e., propagation of dislocations, are not observed in metallic glasses.

Many models or phenomenological theories have been proposed to describe the physical and mechanical properties of amorphous materials. The free volume theory was employed with some success to explain the properties of many glassy materials. ${ }^{46,47}$ However, this theory fails to analyze physical and mechanical properties at microscopic or atomistic level. Other alternative approaches introduced the concept of "defects". It was envisioned that the structural and mechanical properties of the glassy materials are strongly dependent on these "defects". These "defects" correspond to fluctuations of density, entropy, or energy at atomistic or molecular level. A microscopic model of topological fluctuations was developed by Egami. ${ }^{38,39}$ The architecture of these local minima of the potential energy can be described by the potential energy landscape (PEL) concept, initially proposed by De Benedetti and Stillinger. ${ }^{48-51}$ This concept of defects is closely related to the physical behavior (i.e., relaxation mode) and mechanical properties (i.e., plasticity) of amorphous materials. In addition, the concept of shear transformation zones (STZs) was introduced by Argon et al. ${ }^{52,53}$ This is quite similar to the concept of "micro shear domains (MSDs)" proposed by Perez et al. to model the mechanical and physical properties in polymers and also in metallic glasses. ${ }^{35-37}$ Taking the PEL theory and STZs model, cooperative shear mode was developed by Johnson et al. to evaluate the Newtonian as well as non-Newtonian behavior in metallic glasses. ${ }^{54,55}$ The behavior of the glass transition, mechanical deformation, and structural relaxation in metallic glasses can be described well by these theories.

In the current work, we use mechanical spectroscopy to investigate the mechanical relaxation ( $\alpha$ and $\beta$ relaxations) in several typical bulk metallic glasses in isochronal route as well as isothermal mode. We investigated the dependence of the mechanical relaxation on the physical aging to study the evolution of the localized atomic mobility with the physical aging. The contribution of the $\alpha$ and $\beta$ relaxations in mechanical loss spectra in La-and Pd-based metallic glasses is discussed in terms of the Coupling Model. ${ }^{2}$

\section{EXPERIMENTAL SECTION}

Several typical metallic glasses were selected as model materials, such as Pd-based $\left(\mathrm{Pd}_{40} \mathrm{Ni}_{10} \mathrm{Cu}_{30} \mathrm{P}_{20}\right.$ and $\left.\mathrm{Pd}_{43} \mathrm{Ni}_{10} \mathrm{Cu}_{27} \mathrm{P}_{20}\right)$, Labased $\left(\mathrm{La}_{60} \mathrm{Ni}_{15} \mathrm{Al}_{25}, \quad \mathrm{La}_{57.5} \mathrm{Ni}_{12.5} \mathrm{Al}_{17.5} \mathrm{Cu}_{12.5}\right.$ and $\left.\mathrm{La}_{68.5} \mathrm{Ni}_{16} \mathrm{Al}_{14} \mathrm{Co}_{1.5}\right)$, Cu-based $\left(\mathrm{Cu}_{46} \mathrm{Zr}_{45} \mathrm{Al}_{7} \mathrm{Y}_{2}\right)$, Zr-based $\left[\mathrm{Zr}_{41.2} \mathrm{Ti}_{13.8} \mathrm{Cu}_{12.5} \mathrm{Ni}_{10} \mathrm{Be}_{22.5}\right.$ (Vit1) and $\left.\mathrm{Zr}_{61} \mathrm{Ti}_{2} \mathrm{Cu}_{25} \mathrm{Al}_{12}\right]$, Znbased $\left(\mathrm{Zn}_{38} \mathrm{Mg}_{12} \mathrm{Ca}_{32} \mathrm{Yb}_{18}\right)$, Ti-based $\left(\mathrm{Ti}_{40} \mathrm{Zr}_{25} \mathrm{Ni}_{8} \mathrm{Cu}_{9} \mathrm{Be}_{18}\right)$, and Ce-based $\left[\left(\mathrm{Ce}_{0.72} \mathrm{Cu}_{0.28}\right)_{90} \mathrm{Al}_{10}\right]$ (the nominal compositions in the current work are in atomic percent) due to their different relaxation behaviors, excellent glass-forming ability (GFA), and special thermal properties. The amorphous nature of the bulk metallic glasses was confirmed by using a commercial X-ray diffractometer (XRD) (D8, Bruker AXS Gmbh, Germany with copper $\mathrm{K}_{\alpha}$ radiation). Differential scanning calorimetry (DSC) (Perkin-Elmer, DSC-7 under high purity dry nitrogen) was used to investigate the thermal properties of the metallic glasses. The dynamic shear measurements of different bulk metallic glasses were studied by mechanical spectroscopy [also called dynamic mechanical analysis (DMA)] with an inverted forced oscillation pendulum described by Etienne et al. ${ }^{56}$ Experiments were performed using a sinusoidal stress, either at a fixed temperature and a frequency ranges from $10^{-4}$ to $1 \mathrm{~Hz}$ or during continuous heating with a constant heating rate of 3 $\mathrm{K} / \mathrm{min}$ and a constant frequency. Experimental samples, with the dimensions of $30 \mathrm{~mm}$ (length) $\times 2 \mathrm{~mm}$ (width) $\times 1 \mathrm{~mm}$ (thickness), were polished carefully using diamond paste to rule out surface oxidation. All the experimental tests were carried out in a high vacuum atmosphere. A periodic shear stress was applied and the corresponding strain can be obtained. Thus, the complex shear modulus $\left(G=G^{\prime}+i G^{\prime \prime}\right)$ was measured and then storage $\left(G^{\prime}\right)$ and loss $\left(G^{\prime \prime}\right)$ dynamic shear modulus were calculated. Loss factor $\tan \delta=G^{\prime \prime} / G^{\prime}$ was also determined. 


\section{RESULTS AND DISCUSSION}

3.1. Existence of Two Relaxations in Metallic Glasses. Figure 2 displays the dynamic mechanical curves in

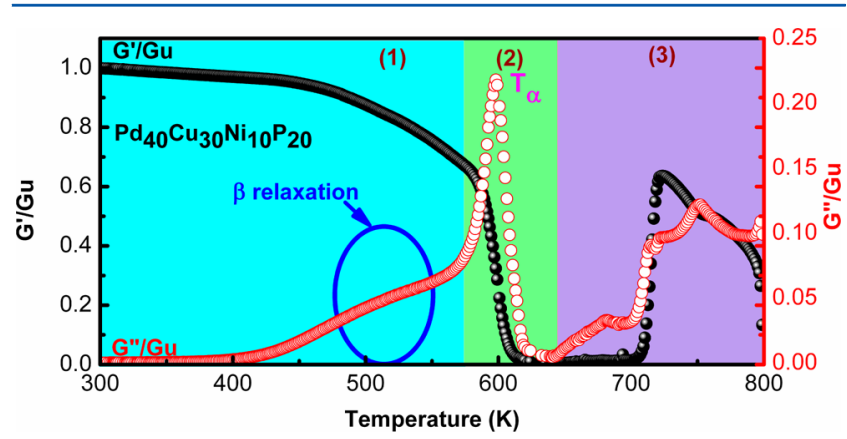

Figure 2. Storage modulus $G^{\prime}$ and loss modulus $G^{\prime \prime}$ vs temperature in $\mathrm{Pd}_{40} \mathrm{Ni}_{10} \mathrm{Cu}_{30} \mathrm{P}_{20}$ bulk metallic glass, $G_{u}$ is the unrelaxed modulus, assumed to be equal to $G^{\prime}$ at room temperature. Experiments are carried out during continuous heating $(3 \mathrm{~K} / \mathrm{min})$ with a constant driving frequency $(0.3 \mathrm{~Hz})$.

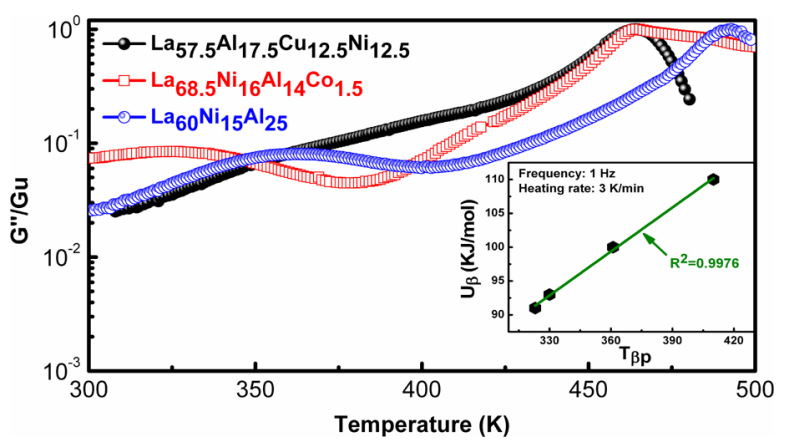

Figure 3. Temperature dependence of the normalized loss modulus $G^{\prime \prime} / G_{\mathrm{u}}$ in typical La-based metallic glasses (heating rate: $3 \mathrm{~K} / \mathrm{min}$ and driving frequency: $0.3 \mathrm{~Hz}$ ). $G_{\mathrm{u}}$ is the unrelaxed modulus, assumed to be equal to $G^{\prime}$ at room temperature. The inset shows the correlation between the apparent activation energy $U_{\beta}$ of the $\beta$ relaxation and the peak temperature $T_{\beta \mathrm{p}}$ of this relaxation. The solid line is the fitting line (the data were obtained from refs 27 and 28).

$\mathrm{Pd}_{40} \mathrm{Ni}_{10} \mathrm{Cu}_{30} \mathrm{P}_{20}$ bulk metallic glass, obtained at a fixed driving frequency $(0.3 \mathrm{~Hz})$ and changing the temperature at a constant heating rate $(3 \mathrm{~K} / \mathrm{min}) . G_{u}$ corresponds to the value of the unrelaxed modulus, i.e., the value of the shear modulus at low temperature. Like for other metallic glasses, in the curve in Figure 2 three temperature ranges are evident, represented in the three distinct colors. Region (I): At low temperature the material is in the amorphous state. $G^{\prime}$ is high and nearly constant and the viscoelastic component $G^{\prime \prime}$ is very low (close to zero $\mathrm{GPa}$ ), so the behavior is mainly elastic in this domain. It should be noted that a fairly pronounced $\beta$ relaxation is observed around $500 \mathrm{~K}$. Region (II): Maximum of $G^{\prime \prime}$ occurs at a temperature called $T_{\alpha}$, which corresponds to the temperature at which the peak frequency of $\alpha$ relaxation is equal to the driving frequency $(0.3 \mathrm{~Hz}$ in this case). This relaxation is related to the dynamic glass transition. A decrease of $G^{\prime}$ occurs as the temperature increases. This temperature range is associated with the supercooled liquid region (SLR) for metallic glasses. Region (III): Both storage modulus $G^{\prime}$ and loss modulus $G^{\prime \prime}$ increase drastically as temperature increases due to the occurrence of the crystallization.
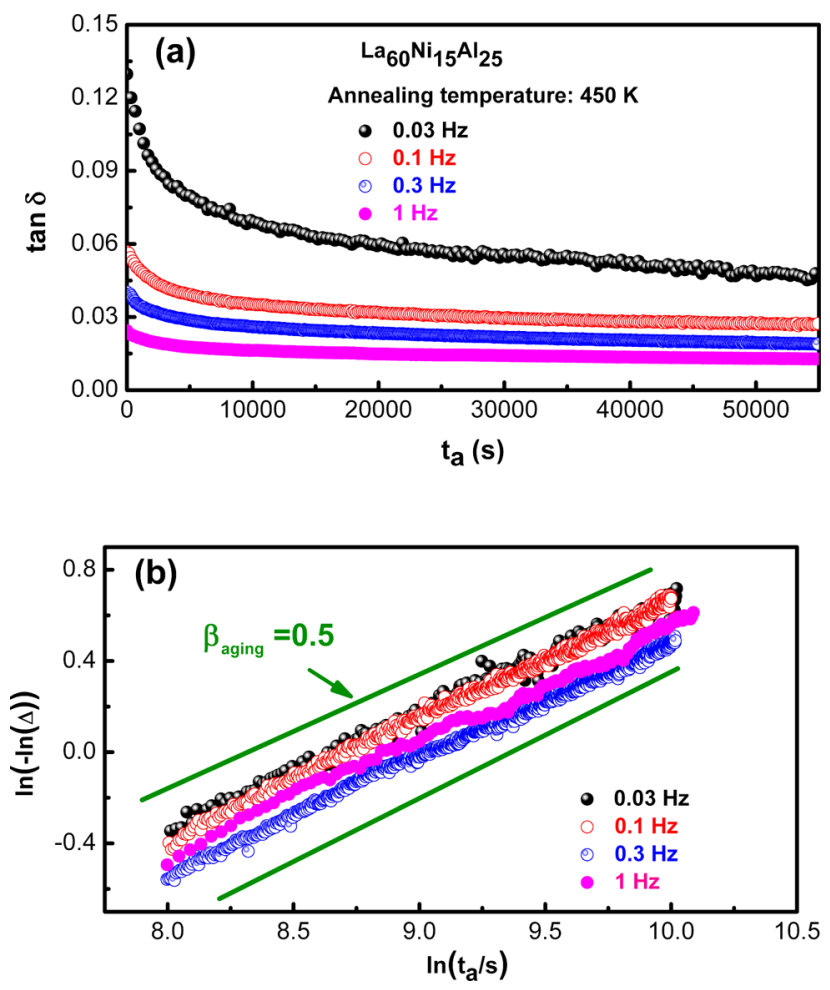

Figure 4. (a) Time dependence of the loss factor $\tan \delta=G^{\prime \prime} / G^{\prime}$ in $\mathrm{La}_{60} \mathrm{Ni}_{15} \mathrm{Al}_{25}$ bulk metallic glass at four different driving frequencies $(0.03-0.1-0.3-1 \mathrm{~Hz})$. The metallic glasses were heated to annealing temperature (below $T_{\mathrm{g}}$ ) $T_{\alpha}=450 \mathrm{~K}$ at a heating rate $3 \mathrm{~K} / \mathrm{min}$, and then held isothermally at $450 \mathrm{~K}$. (b) Double logarithmic plot of the variation of the loss factor $\tan \delta$ vs logarithm of the annealing time in $\mathrm{La}_{60} \mathrm{Ni}_{15} \mathrm{Al}_{25}$ bulk metallic glass at various driving frequencies.

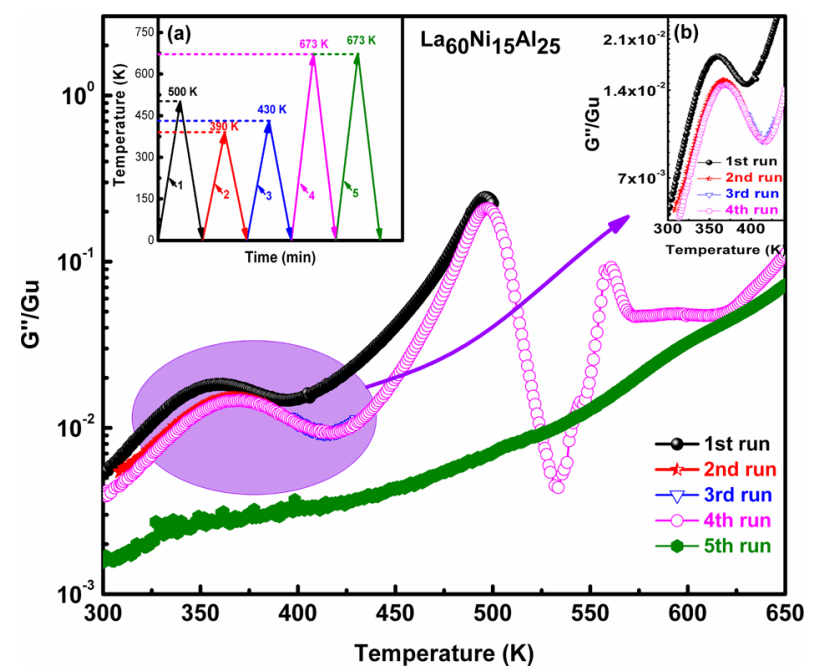

Figure 5. Evolution of the $\beta$ and $\alpha$ relaxations during successive continuous heating processes in $\mathrm{La}_{60} \mathrm{Ni}_{15} \mathrm{Al}_{25}$ bulk metallic glass (heating rate: $3 \mathrm{~K} / \mathrm{min}$ and frequency: $0.3 \mathrm{~Hz}$ ). The inset (a) is a schematic illustration of the DMA experiment and (b) presents the zoom of the $\beta$ relaxation at lower temperature range.

Figure 3 shows the temperature dependence of the normalized loss modulus $\mathrm{G}^{\prime \prime} / \mathrm{G}_{\mathrm{u}}$ in typical La-based $\left(\mathrm{La}_{57.5} \mathrm{Al}_{17.5} \mathrm{Cu}_{12.5} \mathrm{Ni}_{12.5}, \mathrm{La}_{60} \mathrm{Ni}_{15} \mathrm{Al}_{25}\right.$ and $\left.\mathrm{La}_{68.5} \mathrm{Ni}_{16} \mathrm{Al}_{14} \mathrm{Co}_{1.5}\right)$ metallic glasses (Heating rate: $3 \mathrm{~K} / \mathrm{min}$ and driving frequency: $0.3 \mathrm{~Hz})$. A well separated $\beta$ relaxation is observed in $\mathrm{La}_{60} \mathrm{Ni}_{15} \mathrm{Al}_{25}$ and $\mathrm{La}_{68.5} \mathrm{Ni}_{16} \mathrm{Al}_{14} \mathrm{Co}_{1.5}$ bulk metallic glasses, 

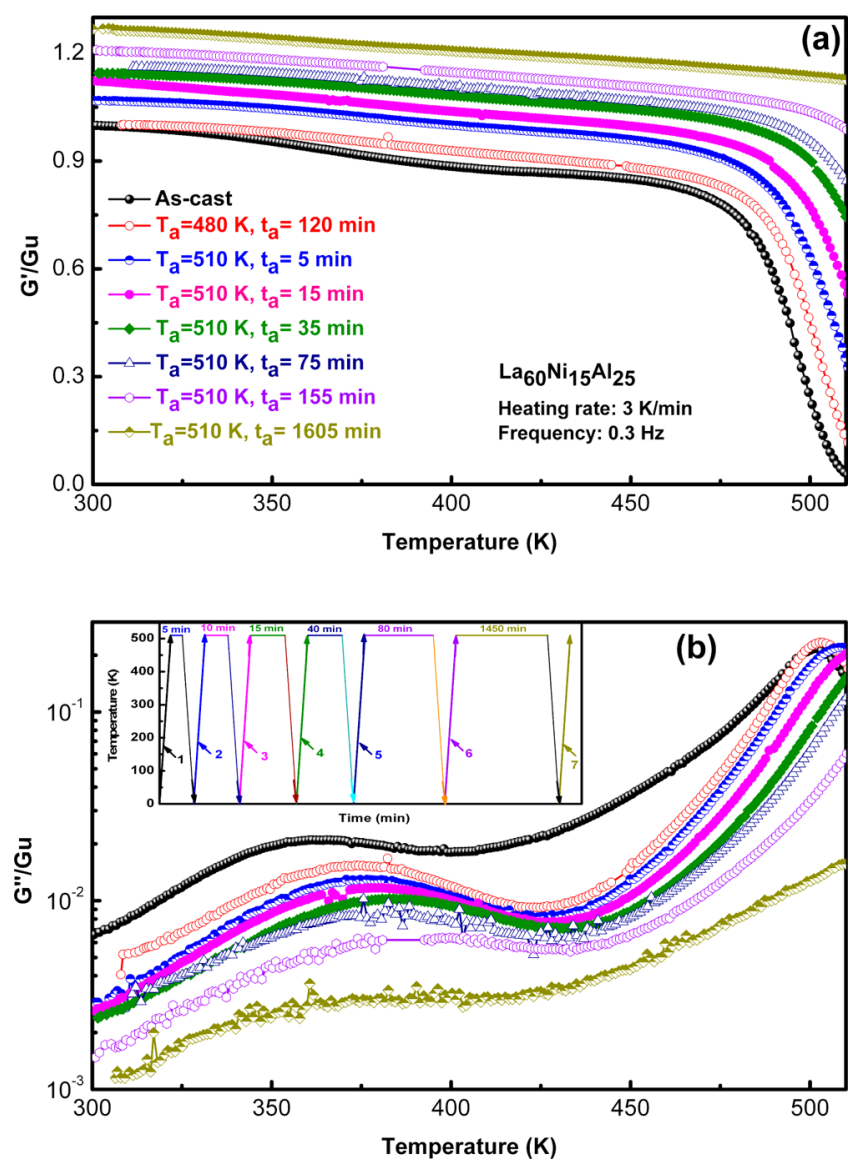

Figure 6. Influence of partial crystallization on the $\beta$ relaxation in $\mathrm{La}_{60} \mathrm{Ni}_{15} \mathrm{Al}_{25}$ bulk metallic glass: (a) Storage modulus $G^{\prime} / G_{\mathrm{u}}$ and (b) loss modulus $G^{\prime \prime} / G_{\mathrm{u}}$ (annealing temperature $T_{\mathrm{a}}=510 \mathrm{~K}$ ). The inset of (b) is a schematic illustration of the DMA experiment at various annealing time ( 1 , as cast; 2 , annealing time is $5 \mathrm{~min}$; 3 , annealing time is $15 \mathrm{~min}$ ). Measurement frequency is $0.3 \mathrm{~Hz}$ and heating rate is $3 \mathrm{~K} /$ min.

while for $\mathrm{La}_{57.5} \mathrm{Al}_{17.5} \mathrm{Cu}_{12.5} \mathrm{Ni}_{12.5}$ the $\beta$ relaxation is more hidden in the low temperature flank of the $\alpha$-relaxation. In the literature, $\beta$ relaxation has been recently correlated to the existence of "soft" region in metallic glasses, corresponding to structural heterogeneities. ${ }^{13,27,28}$ In these regions, movements of atoms are facile and consequently the activation of shear transformation zones (STZs) is enhanced. In addition, nucleation of multiple shear bands in these "soft" domains is responsible for the plasticity of metallic glasses. On the other hand, the resistance in "hard" domains impedes propagation of shear bands during the deformation process. ${ }^{43}$ Thus, the difference in the $\beta$ relaxation evident in the isochronal curves in Figure 3 suggests that the degree of separation in frequency of the two relaxations depends on the difference in the dynamic properties between hard and soft regions more than on the relative amounts of "soft" or "hard" regions. Differences in the mobility of La atoms and the rest of the smaller transition metal components or fluctuations in chemical composition may also be responsible for such differences in the relaxation scenario.

The apparent activation energy of the $\beta$ relaxation in amorphous materials can be calculated from the Arrhenius equation: $f=f_{\infty} \exp \left(-U_{\beta} / R T\right)$, where $R$ is gas constant, and $f_{\infty}$ is prefactor expressing the high $T$ limit. Like for organic glassformers, for a number of metallic glasses, it has been found that $U_{\beta}$ and $T_{g}$ satisfy the relation: $U_{\beta} \approx 26( \pm 2) R T_{g}{ }^{27,32}$ Moreover,
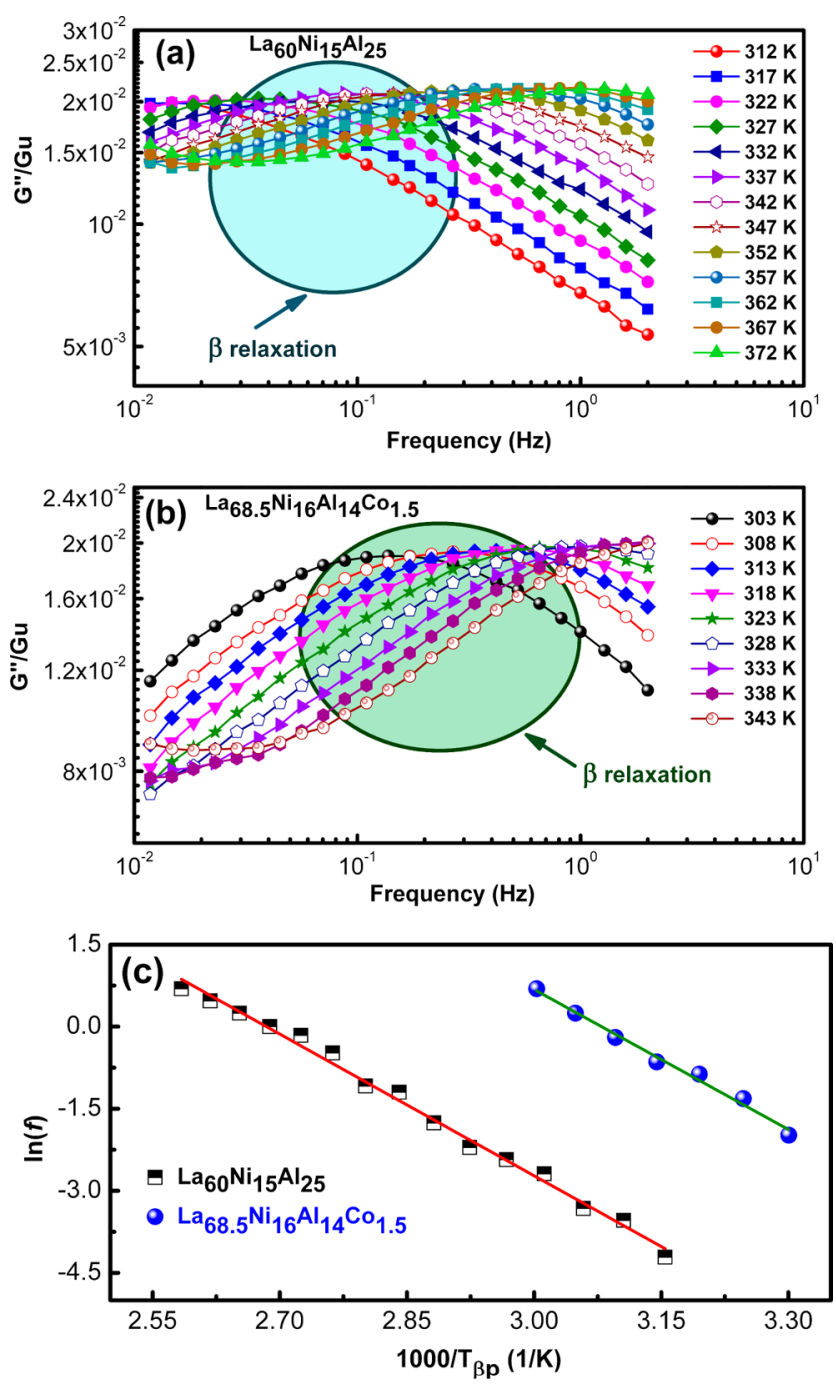

Figure 7. Frequency dependence of the normalized loss modulus spectra $\mathrm{G}^{\prime \prime} / \mathrm{G}_{\mathrm{u}}$ of $\mathrm{La}_{60} \mathrm{Ni}_{15} \mathrm{Al}_{25}$ (a) and $\mathrm{La}_{68.5} \mathrm{Ni}_{16} \mathrm{Al}_{14} \mathrm{Co}_{1.5}$ (b) bulk metallic glasses in isothermal mode at lower temperature domain. (The isothermal temperature is around the $\mathrm{T}_{\beta \mathrm{p}}$.) (c) shows the Arrhenius plots (the solid lines) of the $\beta$ relaxations in $\mathrm{La}_{60} \mathrm{Ni}_{15} \mathrm{Al}_{25}$ and $\mathrm{La}_{68.5} \mathrm{Ni}_{16} \mathrm{Al}_{14} \mathrm{Co}_{1.5}$ bulk metallic glasses.

we observe a linear relation between the peak temperatures $T_{\beta \mathrm{p}}$ of the $\beta$ relaxation and its activation energy $U_{\beta}$, consistent with a linear increase in $U_{\beta}$ with increasing $T_{\beta \mathrm{p}}$ (inset of Figure 3). Thus, a higher activation energy is required to activate local atomic motions in alloys with a higher $T_{\beta \mathrm{p}}$ in metallic glasses. In particular, we found ${ }^{27,28} U_{\beta} \approx 33( \pm 1) R T_{\beta \mathrm{p}}$.

Interestingly, the value in metallic glasses is in good agreement with that reported in amorphous polymers, where $U_{\beta} \approx 31.5 R T_{\beta \mathrm{p}}$ (with a driving frequency of $1 \mathrm{~Hz}$ ). This relation between $U_{\beta}$ and the peak temperatures $T_{\beta \mathrm{p}}$ of $\beta$ relaxation indicates that the high $T$ limit, $f_{\max }$ is approximately the same for all the MGs considered, with $f_{\max } \approx 2 \times 10^{14} \mathrm{~Hz}$.

Here, we investigate the possible common physical origin of the $\beta$ relaxation in polymers and metallic glasses. With the help of the quasi-point defects theory based on a major assumption that density (enthalpy or entropy) fluctuation in amorphous materials corresponds to the quasi-point defects, the global characteristic time of the movement of the atoms or molecules can be described by 

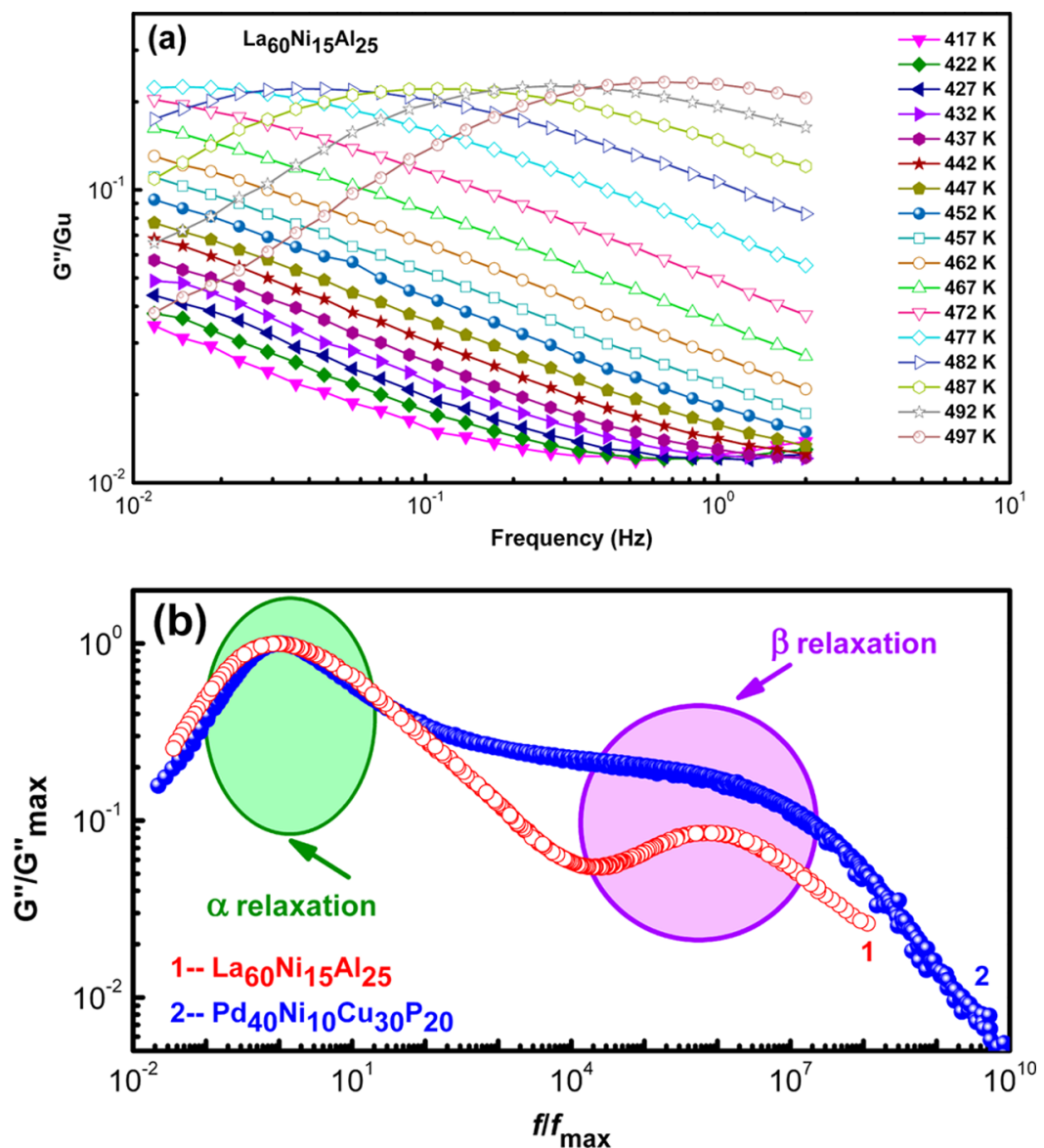

Figure 8. (a) Normalized loss modulus spectra $G^{\prime \prime} / G_{u}$ of $\mathrm{La}_{60} \mathrm{Ni}_{15} \mathrm{Al}_{25}$ bulk metallic glasses as a function of frequency at different temperatures for $\alpha$ relaxation. (b) Master curves for the loss modulus in $\mathrm{La}_{60} \mathrm{Ni}_{15} \mathrm{Al}_{25}{ }^{13}$ and $\mathrm{Pd}_{40} \mathrm{Ni}_{10} \mathrm{Cu}_{30} \mathrm{P}_{20}$ bulk metallic glasses.

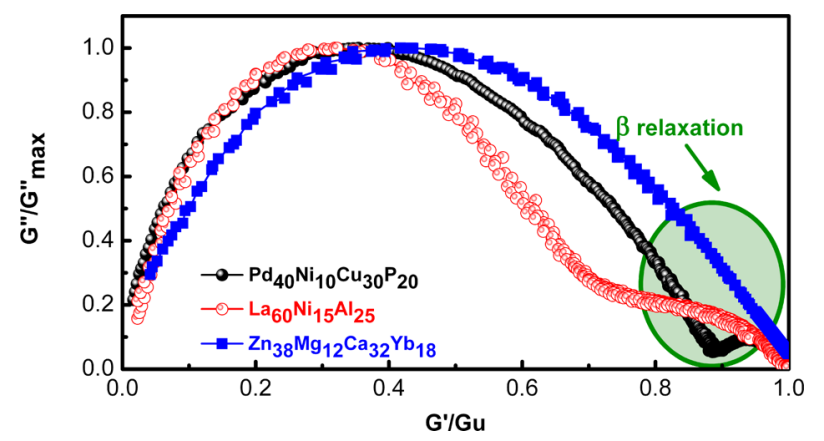

Figure 9. Cole-Cole (CC) plots, i.e., the normalized loss modulus $G^{\prime \prime}$ vs the normalized storage modulus $G^{\prime}$, in $\mathrm{La}_{60} \mathrm{Ni}_{15} \mathrm{Al}_{25}$, $\mathrm{Pd}_{40} \mathrm{Ni}_{10} \mathrm{Cu}_{30} \mathrm{P}_{20}$ and $\mathrm{Zn}_{38} \mathrm{Mg}_{12} \mathrm{Ca}_{32} \mathrm{Yb}_{18}$ bulk metallic glasses.

$$
\tau_{\mathrm{mol}}=t_{0}\left(\frac{\tau_{\mathrm{s}}}{t_{0}}\right)^{1 / \chi}
$$

$\tau_{\text {mol }}$ corresponds to the mean duration of the movement of a structural unit over a distance equal to its dimension, $t_{0}$ is a time scale parameter, $\chi$ is a correlation factor, varying from 0 (fully constrained state) to 1 (constrained-free state). $\tau_{\mathrm{s}}$ is the mean time of the thermally activated jump of a structural unit and is given by Arrhenius law

$$
\tau_{\mathrm{s}}=\tau_{\infty} \exp \left(\frac{U_{\mathrm{s}}}{R T}\right)
$$

where $\tau_{\infty}$ is a high temperature limit, $U_{s}$ is the activation energy, and $R$ the gas constant.

The correlation factor $\chi$ is linked to the quasi-point defect concentration. $\chi=0$ : maximum order, corresponds to a perfect crystal, any movement of a structural unit requires the motion of all other units. $\chi=1$ : maximum disorder, all the movements are independent of each other. The correlation factor $\chi$ is closely connected to the concentration of quasi-point defect and the atomic mobility in amorphous materials. In view of eq 2 , the driving frequency was fixed, i.e., $1 \mathrm{~Hz}$, and $t_{0}=10^{-13}-$ $10^{-12} \mathrm{~s}$ in the metallic glasses and amorphous polymers. Thus, the behavior of the structural unit movement is very similar to what is observed for the $\beta$ relaxation, and it can be assumed that $\tau_{\mathrm{s}} \sim \tau_{\beta}$ and $U_{\mathrm{s}} \sim U_{\beta}$. Interestingly, some phenomenogical behavior like the dependence of the activation energy, $U_{\beta}$, for the $\beta$ relaxation in metallic glasses is similar to that observed in amorphous materials (inset of Figure 3).

Another model often used to interpret the mechanical relaxation behavior of amorphous materials is the Coupling Model (CM) proposed by Ngai et al. ${ }^{2}$ The CM is focused on the many-body nature of the $\alpha$ relaxation in amorphous materials. As a consequence of the heterogeneous dynamics of amorphous materials, the cooperative $\alpha$ relaxation is described by a Kohlrausch stretched exponent function

$$
\varphi(t)=\exp \left[-\left(t / \tau_{\alpha}\right)^{1-n}\right]
$$

with

$$
\tau_{\alpha}=\left[t_{c}^{-n} \tau_{0}\right]^{1 / 1-n}
$$



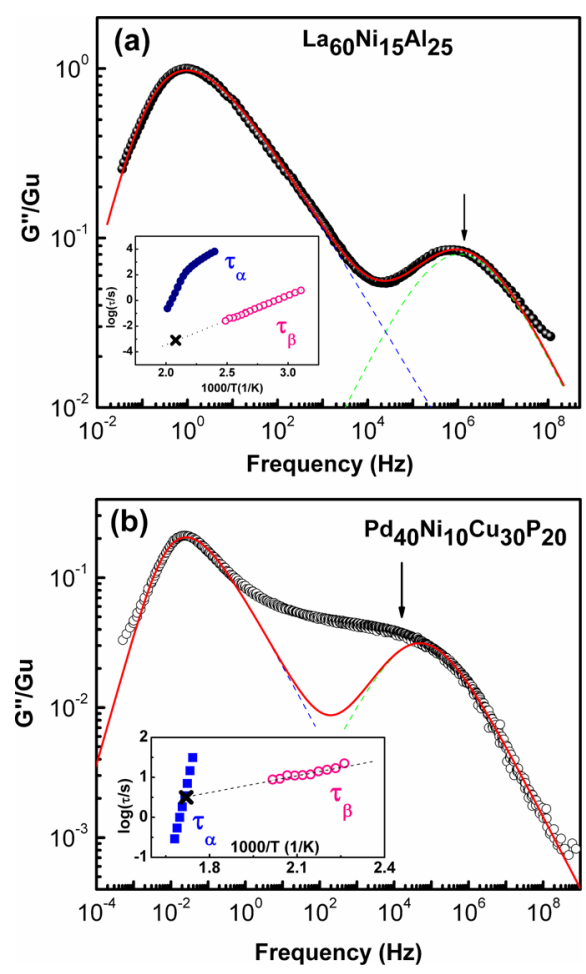

Figure 10. Best fit of the master curve (red solid line) of the loss modulus of $\mathrm{La}_{60} \mathrm{Ni}_{15} \mathrm{Al}_{25}$ (a) and $\mathrm{Pd}_{40} \mathrm{Ni}_{10} \mathrm{Cu}_{30} \mathrm{P}_{20}$ (b) with eq 8; the dotted lines are the individual contributions of the two relaxations. The best fit parameters were for $\mathrm{La}_{60} \mathrm{Ni}_{15} \mathrm{Al}_{25}: \log \left(\tau_{\alpha}\right)=-0.93, \beta_{\mathrm{KWw}}$ $=0.44, \Delta G_{\alpha} / G_{\mathrm{u}}=3.9, \log \left(\tau_{\beta}\right)=-4.76, \Delta G_{\beta} / G_{\mathrm{u}}=0.36 ; a=0.55, b=$ 1; $\mathrm{Pd}_{40} \mathrm{Ni}_{10} \mathrm{Cu}_{30} \mathrm{P}_{20} \log \left(\tau_{\alpha}\right)=0.67, \beta_{\mathrm{KWW}}=0.54, \Delta G_{\alpha} / G^{\prime \prime}{ }_{\text {max }}=0.7$, $\log \left(\tau_{\beta}\right)=-3.9, \Delta G_{\beta} / G^{\prime \prime}{ }_{\text {max }}=0.13 ; a=0.56, b=1$. The arrow is the $\tau_{0}$ of the CM calculated using these parameters. In the inset is the $\log (\tau)$ from the best fit of the isothermal spectra. The symbol $\times$ is the extrapolated $\tau_{\beta}$ at the $\tau_{\alpha}$ of the master curve in the main figure; this value is much smaller than the $\tau_{\beta}$ from the fit of the master curve. These results show that the separation between $\alpha$ and $\beta$ processes is much smaller if determined from the isothermal data than if determined from the master curve.

where $n$ is the coupling parameter of the coupling model and $n$ ranges from 0 to $1 . \tau_{0}$ is the primitive relaxation time and $t_{\mathrm{c}}(\sim 1$ ps) is the temperature insensitive crossover time from exponential to stretched exponential relaxation. The larger is the coupling parameter $n$, the higher is the degree of cooperativity of the dynamics in amorphous materials.

Interestingly, if we compare the predictions of the quasipoint defects theory (eq 1) and the Coupling Model (eqs 3 and 4), we obtain:

$$
\begin{aligned}
& 1-n \equiv \beta_{\mathrm{KWW}}=1 / \chi \\
& t_{0}=t_{\mathrm{c}} \\
& \tau_{0}=\tau_{\mathrm{s}}
\end{aligned}
$$

$1-n$ is the Kohlrausch exponent for which the value is between 0 and 1 , reflecting the deviation from the Debye distribution. Therefore, the predictions of the Coupling Model (CM) and quasi-point defects (QPDs) theory are formally similar.

3.2. Reversibility and Stability of the $\beta$ Relaxation: Case of $\mathrm{La}_{60} \mathrm{Ni}_{15} \mathrm{Al}_{25}$ Metallic Glasses. When amorphous materials are cooled below their glass transition they are "frozen" in a out of equilibrium state. Different thermodynam- ical paths used to induce the glass transition result in glasses with different enthalpy and entropy. Annealing below $T_{g}$ induces physical aging, i.e., structural relaxation toward the thermodynamic equilibrium state.

The structural relaxation can be followed using the evolution of the loss factor $(\tan \delta))$. In such a scenario, the parameter $\Delta$ varied with aging time, $t_{\mathrm{a}}$, by dynamic mechanical analysis experiments: ${ }^{57,58}$

$$
\Delta=\frac{\tan \delta\left(t_{\mathrm{a}}\right)-\tan \delta\left(t_{\mathrm{a}} \rightarrow \infty\right)}{\tan \delta\left(t_{\mathrm{a}}=0\right)-\tan \delta\left(t_{\mathrm{a}} \rightarrow \infty\right)}
$$

By analogy with results obtained by DSC and dielectric ${ }^{9}$ experiments, the following equation has been proposed: ${ }^{57,58}$

$$
\tan \delta\left(t_{\mathrm{a}}\right)-\tan \delta\left(t_{\mathrm{a}}=0\right)=A\left\{1-\exp \left[-\left(t_{\mathrm{a}} / \tau\right)^{\beta_{\text {aging }}}\right]\right\}
$$

where $A$ is the maximum magnitude of the relaxation (= $\tan$ $\left.\delta\left(t_{\mathrm{a}} \rightarrow \infty\right)-\tan \delta\left(t_{\mathrm{a}}=0\right)\right)$. Figure 4(a) displays the evolution of the loss factor tan $\delta$ with annealing time in $\mathrm{La}_{60} \mathrm{Ni}_{15} \mathrm{Al}_{25}$ bulk metallic glass at different driving frequencies $(0.03,0.1,0.3$, and $1 \mathrm{~Hz}$ ) below the glass transition temperature $T_{\mathrm{g}}\left(T_{\mathrm{g}}=461 \mathrm{~K}\right)$. It may be observed that (i) aging leads to a strong decrease in $\tan \delta$ in $\mathrm{La}_{60} \mathrm{Ni}_{15} \mathrm{Al}_{25}$ bulk metallic glass and (ii) the "plateau" value is higher the lower the driving frequency. This is reasonable since the lower frequency is linked to a lower value of the $T_{\alpha}$, and it also corresponds to higher loss factor $\tan \delta$. Figure 4(b) provides information between $\ln (\ln (-\Delta))$ and $\ln \left(t_{a}\right)$ for $\mathrm{La}_{60} \mathrm{Ni}_{15} \mathrm{Al}_{25}$ bulk metallic glass (annealing temperature is $450 \mathrm{~K}$ ). According to eq 7 a linear relationship is observed between $\ln (\ln (-\Delta))$ and $\ln \left(t_{\mathrm{a}}\right)$ from which the values of the Kohlrausch exponent $\beta_{\text {aging }}$ is found to be around 0.5 for all curves, implying that the stretching exponent $\beta_{\text {aging }}$ is independent of the driving frequency at a given aging temperature. In the current study, the annealing temperature is around the glass transition temperature $T_{\mathrm{g}}$. Previously, we found that the stretching exponent $\beta_{\text {aging }}$ is not sensitive to the aging temperature. ${ }^{57}$

We also investigated the influence of physical aging and crystallization on the features of the $\beta$ relaxation in $\mathrm{La}_{60} \mathrm{Ni}_{15} \mathrm{Al}_{25}$ metallic glass. Figure 5 presents the evolution of $\alpha$ and $\beta$ relaxations during successive continuous heating processes in the $\mathrm{La}_{60} \mathrm{Ni}_{15} \mathrm{Al}_{25}$ metallic glass (Heating rate: $3 \mathrm{~K} / \mathrm{min}$ and frequency: $0.3 \mathrm{~Hz}$ ). The first heating (heating up to a temperature above $T_{\mathrm{g}}, T_{\mathrm{g}}=461 \mathrm{~K}$ for $\mathrm{La}_{60} \mathrm{Ni}_{15} \mathrm{Al}_{25}$ metallic glass) erases the previous thermal history. Therefore, curve 2 corresponds to an out of equilibrium glass obtained by cooling at $3 \mathrm{~K} / \mathrm{min}$, while curve 1 is relative to an out of equilibrium state obtained when casting the sample. Curve 2 corresponds to a more stable state that is closer to equilibrium than curve 1 . Aging leads to a decrease in the viscoelastic component, i.e., to a decrease in the atomic mobility. This evolution can be attributed to a progressive decrease in the defect concentration. Further heating up to $430 \mathrm{~K}$ does not induce any change, since $T$ is still below the glass transition: the relaxed state is metastable, and then no structural evolution is induced by heating since the structural relaxation time is much longer than the time of measurement. The features of the $\beta$ relaxation are stable, indicating therefore that this relaxation corresponds to a reversible phenomenon. Similar experimental results have been observed in the previous investigation in $\mathrm{Pd}_{40} \mathrm{Ni}_{10} \mathrm{Cu}_{30} \mathrm{P}_{20}$ metallic glass. Heating to a temperature much higher than $T_{\mathrm{g}}$ leads to a crystallization of the specimen curve 4 . In a crystalline 
specimen the magnitude of the two relaxations $(\beta$ and $\alpha)$ is negligible.

In order to analyze in more detail the influence of crystallization, annealing has been performed at a given temperature above $T_{g}(510 \mathrm{~K})$ but during various annealing times (see the Figure 6). Formation of crystalline particles induces a progressive increase of the elastic component of the shear modulus $\left(G^{\prime}\right)$, and a progressive decrease in the viscoelastic component $\left(G^{\prime \prime}\right)$, especially a decrease in the magnitude of the $\beta$ relaxation. Formation of particles with a long-range order limits the atomic mobility and the degree of heterogeneity in the alloy causing the observed decrease in the magnitude of the mechanical relaxations.

3.3. Master Curves in Metallic Glasses. 3.3.1. Influence of Frequency: $\beta$ Relaxation (Case of La-Based Metallic Glasses). To study the mechanical $\beta$ relaxation in metallic glasses, it is important to consider the influence of the testing frequency on the isothermal spectra of the $\beta$ relaxation. Labased metallic glasses spectra show a well resolved $\beta$-relaxation. By increasing the temperature, the peak frequency of the $\beta$ process in the loss modulus increases. The speeding up of the $\beta$ process by increasing the temperature indicates a higher atomic mobility in soft domains at higher temperature. In agreement with the QPD model (eq 2) the temperature dependence of the peak frequency of the $\beta$ relaxation exhibits Arrhenius-type relationship. In Figure 7 are shown the normalized loss modulus isothermal spectra $G^{\prime \prime} / G_{\mathfrak{u}}$ of $\mathrm{La}_{60} \mathrm{Ni}_{15} \mathrm{Al}_{25}$ and $\mathrm{La}_{68.5} \mathrm{Ni}_{16} \mathrm{Al}_{14} \mathrm{Co}_{1.5}$ bulk metallic glasses below $T_{\mathrm{g}}$. The peak frequency obtained for the spectra are reported in the Arrhenius plots in Figure $7(\mathrm{c})$. The activation energies $\left(U_{\beta}\right.$ $\sim 1 \mathrm{eV}$ ) are in good agreement with the empirical correlation between $U_{\beta}$ and the glass transition temperature $T_{\mathrm{g}}: \mathrm{U}_{\beta} \approx$ $26( \pm 2) R T_{\mathrm{g} \cdot}{ }^{27,32}$

3.3.2. Influence of Frequency: $\alpha$ Relaxation. In Figure 8(a) are reported the isothermal loss modulus $G^{\prime \prime} / G_{u}$ spectra at different temperatures for $\mathrm{La}_{60} \mathrm{Ni}_{15} \mathrm{Al}_{25}$ bulk metallic glass. With decreasing temperature the peak frequency of the $\alpha$-peak in the loss modulus $G^{\prime \prime}$ decreases. With the assumption of the timetemperature superposition principle, a master curve can be plotted for the loss modulus $G^{\prime \prime} / G_{u}$ in $\mathrm{Pd}_{40} \mathrm{Ni}_{10} \mathrm{Cu}_{30} \mathrm{P}_{20}$ and $\mathrm{La}_{60} \mathrm{Ni}_{15} \mathrm{Al}_{25}$ bulk metallic glasses in a large frequency domain (Figure 8(b)).

The Cole-Cole representation, $G^{\prime \prime}$ versus $G^{\prime}$, can also be used to describe the mechanical relaxation behavior in amorphous materials (Figure 9). A single semicircle would correspond to a Debye-like process, an asymmetric arc to a KWW-like process, and multiple arcs to multiple processes. The Cole-Cole plot for the $\mathrm{La}_{60} \mathrm{Ni}_{15} \mathrm{Al}_{25}$ bulk metallic glasses shows a pronounced inflection corresponding to a well separated $\beta$ relaxation, while the $\mathrm{Pd}_{40} \mathrm{Ni}_{10} \mathrm{Cu}_{30} \mathrm{P}_{20}$ metallic glass exhibits a pronounced shoulder in the range $0.6<G^{\prime} / G_{u}$ $<1$, which is associated with an "excess wing". In $\mathrm{Zn}_{38} \mathrm{Mg}_{12} \mathrm{Ca}_{32} \mathrm{Yb}_{18}$ bulk metallic glass, the Cole-Cole diagram displays a nearly symmetrical semicircle and the $\beta$ relaxation is not detected in the current study.

3.4. Analysis of the Mechanical Relaxation in Metallic Glasses. In previous publications we have shown that the Debye model fails to describe the $\alpha$ relaxation in metallic glasses. ${ }^{59-61}$ The loss modulus spectra can be described by the superposition of the Kohlrausch-Williams-Watts (KWW) relaxation function for the $\alpha$ relaxation and the HavriliakNegami (HN) equation for the $\beta$ process. ${ }^{62,63}$

$$
G^{*}(\omega)=G_{\infty}+\Delta G_{\alpha} L_{\mathrm{i} \omega}\left[-\frac{\mathrm{d} \phi_{\alpha}\left(t, \tau_{a}\right)}{\mathrm{d} t}\right]+\frac{\Delta G_{\beta}}{\left[1+\left(i \omega \tau_{\beta}\right)^{a}\right]^{b}}
$$

with $\varphi_{\alpha}\left(t, \tau_{\alpha}\right)=\exp \left[-\left(t / \tau_{\alpha}\right)^{\beta_{\mathrm{KWW}}}\right] . \beta_{\mathrm{KWw}}$ is the Kohlrausch exponent of value between 0 and 1 , reflecting the deviation from the Debye distribution. $\Delta G_{\alpha}$ and $\Delta G_{\beta}$ are the relaxation strength of the $\alpha$ relaxation and $\beta$ relaxation, respectively; $L_{\mathrm{i} \omega}$ is the Laplace transform. The parameters $a$ and $b$ are the shape parameters with values generally between 0 and 1 ; the case $b=$ 1 corresponds to the Cole-Cole equation which is often found to describe the $\beta$ processes well which have very broad and approximately symmetric spectra.

Figure 10 shows the master curve of the loss modulus $G^{\prime \prime} / G_{u}$ fitted by the eq 8 in $\mathrm{La}_{60} \mathrm{Ni}_{15} \mathrm{Al}_{25}$ and $\mathrm{Pd}_{40} \mathrm{Ni}_{10} \mathrm{Cu}_{30} \mathrm{P}_{20}$ bulk metallic glasses; the best fit parameters are in the caption. In the cases, of $\mathrm{La}_{60} \mathrm{Ni}_{15} \mathrm{Al}_{25}$ metallic glasses, the Kohlrausch exponents $\beta_{\mathrm{KWW}}=0.44$, which is quite close to the value of the $\beta_{\text {aging }}$ found in the aging experiment for the same material. Using eq 8 (with $\Delta G_{\beta}=0$ ) to fit the isothermal spectra of the $\alpha$ relaxation we found $\beta_{\mathrm{KWW}}=0.48-0.49$.

Within the framework of the Coupling Model (eq 4), if it is assumed that the $\beta$ relaxation time is about the primitive relaxation time, $\tau_{\beta} \sim \tau_{0}$, the $\mathrm{CM}$ can be used to predict the separation between $\tau_{\alpha}$ and $\tau_{\beta}$ as

$$
\log \tau_{\alpha}-\log \tau_{\beta}=n\left(\log \tau_{\alpha}-\log t_{c}\right)
$$

where the coupling parameter $n=1-\beta_{\mathrm{KWw}}$. The peak frequencies calculated using eq $9\left(f_{\text {peak }}=1 / 2 \pi \tau_{\max }\right)$ with the best fit parameters to the master curves are reported in Figure 10 as arrows. In both cases the arrows are quite close to the peak frequency of the $\beta$ process. On the other hand, the limit of the validity of using the master curves for this analysis needs to be considered. In fact the construction of the master curve assumes that the shape of the spectra is independent of temperature. When a spectrum consists of the superposition of two processes (like herein), then even if the shape and intensity of each process does not change with temperature but the two processes have very different temperature dependences, it is unavoidable that the spectra given by the superposition of these two processes will have a different shape at different temperatures. For these reasons we best fitted the isothermal spectra of the $\alpha$ and $\beta$ (Figure 8) processes and compared the separation of the relaxation times from the isothermal measurements with that from the master curve $\left(\tau_{\alpha}\right.$ and $\tau_{\beta}$ are in the inset to Figure 10). In the analysis of the isothermal spectra we considered only the spectra in which a peak maximum was present. Since the two processes are well separated in frequency (over 5 decades, see inset to Figure 10) the superposition is limited, and we could fit the spectra with a single relaxation function (a KKW function for the $\alpha$ relaxation and a Cole-Cole function for the $\beta$ relaxation). The available frequency range evidently poses some limit to this type of analysis; however, we find that the separation between the $\alpha$ and $\beta$ processes in these cases is several orders of magnitude smaller than what is predicted from the CM.

\section{CONCLUSIONS}

Mechanical spectroscopy was employed to study the mechanical relaxation in typical metallic glasses. In the spectra of all metallic glasses two relaxation processes are evident: (i) a more prominent $\alpha$ relaxation with a VFT-like temperature 
behavior analogous to that found in other classes of amorphous materials and (ii) a faster $\beta$ relaxation, for which the magnitude and frequency separation from the $\alpha$ depends strongly on the composition of the metallic glasses.

We found that both intensity and relaxation time of the $\beta$ process in the glassy state are strongly dependent, in a reproducible fashion, on the thermal history of the sample. When the MGs is formed by a faster quenching, the $\beta$ process has a larger intensity and relaxation time. Then during aging below $T_{g}$ both the intensity and the relaxation time of the $\beta$ process decrease with aging time. The temperature dependence of the $\tau_{\beta}$ in the glassy state is well described by an Arrhenius behavior, with an activation energy $U_{\beta}$. Like for organic glass formers, the ratio $U_{\beta} / R T_{\mathrm{g}} \sim 24$. Moreover, it has been found that the activation energy $U_{\beta}$ and the peak temperatures $T_{\beta \mathrm{p}}$ of the $\beta$ relaxation are related as $U_{\beta} \approx 31.5 R T_{\beta \mathrm{p}}$ (for a driving frequency $1 \mathrm{~Hz}$ ), indicating that the high $T$ limit, $f_{\max }$ is approximately the same for all the MG considered.

The master curves of the loss modulus evidence the contribution of the $\alpha$ and $\beta$ relaxations to the mechanical spectra. The master curves were fitted as a superposition of two relaxation functions. We find that the difference between $\tau_{\alpha}$ and $\tau_{\beta}$ from the best fit parameters of the master curves is in reasonable agreement with the prediction of the Coupling Model; however, we do not find a good agreement with the Coupling Model from the best fit of the isothermal spectra. Further studies with a more extended frequency range will help to better clarify this point.

\section{AUTHOR INFORMATION}

\section{Corresponding Author}

*Tel: +33 4724383 18. Fax: +33 4724385 28. E-mail address: jean-marc.pelletier@insa-lyon.fr.

\section{Notes}

The authors declare no competing financial interest.

\section{ACKNOWLEDGMENTS}

The authors appreciate Dr. K. L. Ngai for valuable discussions and suggestions. One of the authors, J. C. Qiao, would like to thank the Centre National de la Recherche Scientifique (CNRS) for providing the postdoctoral financial support. $\mathrm{R}$. Casalini acknowledges the support of the Office of Naval Research for the work at NRL. We thank W. H. Wang's group (Institute of Physics, CAS) for providing the samples.

\section{REFERENCES}

(1) Capaccioli, S.; Paluch, M.; Prevosto, D.; Wang, L. M.; Ngai, K. L. Many-body Nature of Relaxation Processes in Glass-Forming Systems. J. Phys. Chem. Lett. 2012, 3, 735-743.

(2) Ngai, K. L. Relaxation and Diffusion in Complex Systems; Springer: New York; 2011.

(3) Pawlus, S.; Mierzwa, M.; Paluch, M.; Rzoska, S. J.; Roland, C. M. Dielectric and Mechanical Relaxation in Isooctylcynobiphenyl (8*OCB). J. Phys.: Condens. Matter 2010, 22, 235101.

(4) Hecksher, T.; Nielsen, A. I.; Olsen, N. B.; Dyre, J. C. Little Evidence for Dynamic Divergences in Ultraviscous Molecular Liquids. Nat. Phys. 2008, 4, 737-741.

(5) Pelletier, J. M.; Louzguine-Luzgin, D. V.; Li, S.; Inoue, A. Elastic and Viscoelastic Properties of Glassy, Quasicrystalline and Crystalline Phases in $\mathrm{Zr}_{65} \mathrm{Cu}_{5} \mathrm{Ni}_{10} \mathrm{Al}_{7.5} \mathrm{Pd}_{12.5}$ Alloys. Acta Mater. 2011, 59, 27972806.

(6) Pelletier, J. M.; Perez, J.; Duffrene, L. Mechanical Response of An Oxide Glass to Mechanical Loading-Shear and Volume Relaxation Effects: Physical Analysis. Acta Mater. 2000, 48, 1397-1408.
(7) Leslie-Pelecky, D. L.; Birge, N. O. Universal Scaling of the Relaxation near a Model Glass Transition. Phys. Rev. Lett. 1994, 72, $1232-1235$.

(8) Pineda, E.; Bruna, P.; Ruta, B.; Gonzalez-Silveira, M.; Crespo, D. Relaxation of Rapidly Quenched Metallic Glasses: Effect of the Relaxation State on the Slow Low Temperature Dynamics. Acta Mater. 2013, 61, 3002-3011.

(9) Casalini, R.; Roland, C. M. Aging of the Secondary Relaxation to Probe Structural Relaxation in the Glassy State. Phys. Rev. Lett. 2009, 102, 035701.

(10) Johari, G. P.; Goldstein, M. Viscous Liquids and the Glass Transition. II. Secondary Relaxations in Glasses of Rigid Molecules. J. Chem. Phys. 1970, 53, 2372-2388.

(11) Kessairi, K.; Capaccioli, S.; Prevosto, D.; Lucchesi, M.; Sharifi, S.; Rolla, P. A. Interdependence of Primary and Johari-Goldstein Secondary Relaxations in Glass-Forming Systems. J. Phys. Chem. B 2008, 112, 4470-4473.

(12) Casalini, R.; Roland, C. M. Excess Wing in the Dielectric Loss Spectra of Propylene Glycol Oligomers at Elevated Pressure. Phys. Rev. B 2004, 69, 094202.

(13) Qiao, J. C.; Pelletier, J. M. Dynamic Mechanical Analysis in Labased Bulk Metallic Glasses: Secondary $(\beta)$ and Main $(\alpha)$ Relaxations. J. Appl. Phys. 2012, 112, 083528.

(14) Ngai, K. L.; Paluch, M. Influence of the Evolution from Caged Dynamics to Cooperative Relaxation in Glass-Formers from Dielectric Relaxation Data. J. Phys. Chem. B 2003, 107, 6865-6872.

(15) Munch, E.; Pelletier, J. M.; Sixou, B.; Vigier, G. Characterization of the Drastic Increase in Molecular Mobility of a Deformed Amorphous Polymer. Phys. Rev. Lett. 2006, 97, 207801.

(16) Rinaldi, R.; Gaertner, R.; Chazeau, L.; Gauthier, C. Modelling of the Mechanical Behaviour of Amorphous Glassy Polymer Based on the Quasi Point Defect Theory-Part I: Uniaxial Validation on Polycarbonate. Int. J. Nonlinear Mech. 2011, 46, 496-506.

(17) Ngai, K. L.; Capaccioli, S. Relation Between the Activation Energy of the Johari-Goldstein $\beta$ Relaxation and $T_{g}$ of Glass Formers. Phys. Rev. E 2004, 69, 031501.

(18) Ngai, K. L. Relation Between Some Secondary Relaxations and the $\alpha$ Relaxations in Glass-Forming Materials According to the Coupling Model. J. Chem. Phys. 1998, 109, 6982-6994.

(19) Wang, W. H. The Elastic Properties, Elastic Models and Elastic Perspectives of Metallic Glasses. Prog. Mater. Sci. 2012, 57, 487-656.

(20) Greer, A. L. Metallic Glasses. Science 1995, 267, 1947-1953.

(21) Wang, W. H.; Dong, C.; Shek, C. H. Bulk Metallic Glasses. Mater. Sci. Eng., R 2004, 44, 45-89.

(22) Inoue, A. Stabilization of Metallic Supercooled Liquid and Bulk Amorphous Alloys. Acta Mater. 2000, 48, 279-306.

(23) Wang, W. H. Bulk Metallic Glasses with Functional Physical Properties. Adv. Mater. 2009, 21, 4524-4544.

(24) Pelletier, J. M.; Van de Moortèle, B.; Lu, I. R. Viscoelasticity and viscosity of $\mathrm{Pd}-\mathrm{Ni}-\mathrm{Cu}-\mathrm{P}$ bulk metallic glasses. Mater. Sci. Eng., A 2002, 336, 190-195.

(25) Wang, Z.; Wen, P.; Huo, L. S.; Bai, H. Y.; Wang, W. H. Signature of Viscous Flow Units in Apparent Elastic Regime of Metallic Glasses. Appl. Phys. Lett. 2012, 101, 121906.

(26) Yu, H. B.; Samwer, K.; Wu, Y.; Wang, W. H. Correlation between $\beta$ Relaxation and Self-Diffusion of the Smallest Constituting Atoms in Metallic Glasses. Phys. Rev. Lett. 2012, 109, 095508.

(27) Yu, H. B.; Shen, X.; Wang, Z.; Gu, L.; Wang, W. H.; Bai, H. Y. Tensile Plasticity in Metallic Glasses with Pronounced $\beta$ Relaxation. Phys. Rev. Lett. 2012, 108, 015504.

(28) Wang, Z.; Yu, H. B.; Wen, P.; Bai, H. Y.; Wang, W. H. Pronounced Slow $\beta$-Relaxation in La-based Bulk Metallic Glasses. J. Phys.: Condens. Matter 2011, 23, 142202.

(29) Guo, L. J.; Wu, X. B.; Zhu, Z. G. Mechanical Relaxation Studies of $\alpha$ and Slow $\beta$ Processes in $\mathrm{Nd}_{65} \mathrm{Fe}_{15} \mathrm{Co}_{10} \mathrm{Al}_{10}$ Bulk Metallic Glass. J. Appl. Phys. 2011, 109, 113524.

(30) Qiao, J. C.; Pelletier, J. M.; Kou, H. C.; Zhou, X. Modification of Atomic Mobility in a Ti-based Bulk Metallic Glass by Plastic 
Deformation or Thermal Annealing. Intermetallics 2012, 128, 128137.

(31) Wang, Q.; Pelletier, J. M.; Blandin, J. J. Thermal Stability of Cerium-based Bulk Metallic Glasses. Influence of Iron Addition. J. Alloys Compd. 2010, 504, 357-361.

(32) Yu, H. B.; Wang, W. H.; Bai, H. Y.; Wu, Y.; Chen, M. W. Relating Activation of Shear Transformation Zones to $\beta$ Relaxations in Metallic Glasses. Phys. Rev. B 2010, 81, 220201.

(33) Yu, H. B.; Samwer, K.; Wang, W. H.; Bai, H. Y. Chemical influence on b-relaxations and the formation of molecule-like metallic glasses. Nat. Commun. 2013, 4, 2204.

(34) Liang, D. D.; Wang, X. D.; Ge, K.; Cao, Q. P.; Jiang, J. Z. Annealing Effect on beta-Relaxation in a La-based Bulk Metallic Glass. J. Non-Cryst. Solids 2013, doi: http://dx.doi.org/10.1016/j.jnoncrysol. 2013.03.036.

(35) Perez, J.; Cavaillé, J. Y.; Etienne, S.; Fouquet, F.; Guyot, F. Internal Friction in Vitreous Solid to Glass Transition. Ann. Phys. 1983, 8, 417-467.

(36) Perez, J. Defect Diffusion Model for Volume and Enthalpy Recovery in Amorphous Polymers. Polymer 1988, 29, 483-489.

(37) Perez, J. Quasi-Punctual Defects in Vitreous Solids and LiquidGlass Transition. Solid State Ionics 1990, 39, 69-79.

(38) Egami, T.; Levashov, V.; Aga, R. S.; Morris, J. R. Atomic Dynamics in Metallic Liquids and Glasses. Mater. Trans. 2007, 48, 1729-1733.

(39) Egami, T.; Poon, S. J.; Zhang, Z.; Keppens, V. Glass transition in metallic glasses: A microscopic model of topological fluctuations in the bonding network. Phys. Rev. B 2007, 76, 024203.

(40) Ichitsubo, T.; Matsubara, E.; Chen, H. S.; Saida, J.; Yamamoto, T.; Nishiyama, N. Structural instability of metallic glasses under radiofrequency-Ultrasonic Perturbation and its Correlation with Glass-toCrystal Transition of Less-Stable Metallic glasses. J. Chem. Phys. 2006, $125,154502$.

(41) Ichitsubo, T.; Matsubara, E.; Yamamoto, T.; Chen, H. S.; Nishiyama, N.; Saida, J.; Anazawa, K. Microstructure of Fragile Metallic Glasses Inferred from Ultrasound-Accelerated Crystallization in Pd-Based Metallic Glasses. Phys. Rev. Lett. 2005, 95, 245501.

(42) Zhao, Z. F.; Wen, P.; Shek, C. H.; Wang, W. H. Relaxation Behavior on High Frequency Profile in Strong/Fragile Metallic GlassForming Systems. J. Non-Cryst. Solids 2010, 356, 1198-1200.

(43) Liu, Y. H.; Wang, G.; Wang, R. J.; Zhao, D. Q.; Pan, M. X.; Wang, W. H. Super Plastic Bulk Metallic Glasses at Room Temperature. Science 2007, 315, 1385-1388.

(44) Yang, Y.; Ye, J. C.; Lu, J.; Wang, Q.; Liaw, P. K. Revelation of the Effect of Structural Heterogeneity on Microplasticity in Bulk Metallic-Glasses. J. Mater. Res. 2010, 25, 563-575.

(45) Lee, M. H.; Lee, J. K.; Kim, K. T.; Thomas, J.; Das, J.; Kühn, U.; Eckert, J. Deformation-induced Microstructural Heterogeneity in Monolithic $\mathrm{Zr}_{44} \mathrm{Ti}_{11} \mathrm{Cu}_{9.8} \mathrm{Ni}_{10.2} \mathrm{Be}_{25}$ Bulk Metallic Glass. Phys. Status Solidi RRL 2009, 3, 46-48.

(46) Turnbull, D.; Cohen, M. H. Free-Volume Model of the Amorphous Phase: Glass Transition. J. Chem. Phys. 1961, 34, 120125.

(47) Turnbull, D.; Cohen, M.H.. On the Free-Volume Model of the Liquid-Glass Transition. J. Chem. Phys. 1970, 52, 3038-3041.

(48) Debenedetti, P. G.; Stillinger, F. H. Supercooled Liquids and the Glass Transition. Nature 2001, 410, 259-267.

(49) Stillinger, F. H. A Topographic View of Supercooled Liquids and Glass Formation. Science 1995, 267, 1935-1939.

(50) Stillinger, F. H. Enumeration of Isobaric Inherent Structures for the Fragile Glass Former Ortho-Terphenyl. J. Phys. Chem. B 1998, 102, 2807-2810.

(51) Debenedetti, P. G.; Stillinger, F. H.; Shell, M. S. Model Energy Landscapes. J. Phys. Chem. B 2003, 107, 14434-14442.

(52) Argon, A. S. Plastic Deformation in Metallic Glasses. Acta Metall. 1979, 27, 47-58.

(53) Argon, A. S.; Shi, L. T. Development of Visco-Plastic Deformation in Metallic Glasses. Acta Metall. 1983, 31, 499-507.
(54) Johnson, W. L.; Samwer, K. A Universal Criterion for Plastic Yielding of Metallic Glasses with a $\left(\mathrm{T} / \mathrm{T}_{\mathrm{g}}\right)^{2 / 3}$ Temperature Dependence. Phys. Rev. Lett. 2005, 95, 195501.

(55) Johnson, W. L.; Demetriou, M. D.; Harmon, J. S.; Lind, M. L.; Samwer, K. Rheology and Ultrasonic Properties of Metallic GlassForming Liquids: A Potential Energy Landscape Perspective. MRS Bull. 2007, 32, 644-650.

(56) Etienne, S.; Cavaillé, J. Y.; Perez, J.; Point, R.; Salvia, M. Automatic System for Analysis of Micromechanical Properties. Rev. Sci. Instrum. 1982, 53, 1261-1266.

(57) Qiao, J. C.; Pelletier, J. M. Kinetics of Structural Relaxation in Bulk Metallic Glasses by Mechanical Spectroscopy: Determination of the Stretching Parameter $\beta_{K W W}$. Intermetallics 2012, 28, 40-44.

(58) Pelletier, J. M. Influence of Structural Relaxation on Atomic Mobility in a $\mathrm{Zr}_{41.2} \mathrm{Ti}_{13.8} \mathrm{Cu}_{125} \mathrm{Ni}_{10.0} \mathrm{Be}_{22.5}$ (Vit1) Bulk Metallic Glass. J. Non-Cryst. Solids 2008, 354, 3666-3670.

(59) Qiao, J. C.; Pelletier, J. M. Mechanical Relaxation in a Zr-based Bulk Metallic Glass: Analysis Based on Physical Models. J. Appl. Phys. 2012, 112, 033518.

(60) Pelletier, J. M. Dynamic Mechanical Properties in a $\mathrm{Zr}_{46.8} \mathrm{Ti}_{13.8} \mathrm{Cu}_{12.5} \mathrm{Ni}_{10} \mathrm{Be}_{27.5}$ Bulk Metallic Glass. J. Alloys Compd. 2005, 393, 223-230.

(61) Pelletier, J. M.; Van de Moortèle, B. Viscoelasticity of Metallic, Polymeric and Oxide Glasses Common Features and Differences. Mater. Sci. Eng., A 2006, 442, 250-255.

(62) Casalini, R.; Snow, A. W.; Roland, C. M. Temperature Dependence of the Johari-Goldstein Relaxation in Poly(methyl methacrylate) and Poly(thiomethyl methacrylate). Macromolecules 2013, 46, 330-334.

(63) Casalini, R.; Fragiadakis, D.; Roland, C. M. Relaxation Dynamics of Poly(methyl acrylate) at Elevated Pressure. Macromolecules 2011, 44, 6928-6934. 